Fanum

Sociológico
Forum Sociológico

Série II

$18 \mid 2008$

Explorando os interstícios urbanos

\title{
Interstícios urbanos e o conceito de espaço exterior positivo
}

\section{Maria Rosália Guerreiro}

\section{(2) OpenEdition \\ Journals}

Edição electrónica

URL: https://journals.openedition.org/sociologico/218

DOI: 10.4000/sociologico. 218

ISSN: 2182-7427

Editora

CICS.NOVA - Centro Interdisciplinar de Ciências Sociais da Universidade Nova de Lisboa

Edição impressa

Data de publição: 1 junho 2008

Paginação: 13-19

ISSN: 0872-8380

\section{Refêrencia eletrónica}

Maria Rosália Guerreiro, «Interstícios urbanos e o conceito de espaço exterior positivo», Forum Sociológico [Online], 18 | 2008, posto online no dia 19 julho 2012, consultado o 29 março 2022. URL: http://journals.openedition.org/sociologico/218; DOl: https://doi.org/10.4000/sociologico.218

Este documento foi criado de forma automática no dia 29 março 2022.

(c) CICS.NOVA 


\title{
Interstícios urbanos e o conceito de espaço exterior positivo
}

\author{
Maria Rosália Guerreiro
}

\section{Introdução}

1 O conceito de interstício é uma oportunidade para estudos interdisciplinares. O meu interesse nesta temática emerge da área do urbanismo e olha para a cidade como um objecto de arquitectura. $\mathrm{O}$ termo tem origem na biologia e é muito adequado para o estudo dos espaços urbanos orgânicos que tiveram um crescimento progressivo, espontâneo, que tem uma aparência irregular e aparentemente caótica.

2 Do ponto de vista urbano, tem muito interesse tomar como objecto de estudo, ou seja, como forma, o espaço de fundo definido pelos edifícios. Este aspecto tem grande influência na qualidade estrutural do espaço urbano e consequentemente na sua apropriação por parte das pessoas.

3 Nesta forma de organização, irregular mas coerente, a geometria euclidiana, instrumento fundamental para a arquitectura, perde o pé, ganhando terreno o conhecimento desenvolvido noutras ciências, como a física e a biologia. Esta perspectiva de ordem em arquitectura, que se aproxima da ordem na natureza, caminha junto com a mudança do paradigma racionalista e cartesiano para uma visão holística e sistémica do mundo, bem como duma aproximação cada vez maior entre arte e ciência.

4 O objectivo deste trabalho é dar a conhecer a qualidade estrutural dos espaços urbanos orgânicos, comparativamente com outros modelos de cidade, e o modo como essa qualidade interfere no uso desses mesmos espaços pelas pessoas. Sendo este o modelo de cidade que mais interessa na actualidade aos profissionais de planeamento pela sua forte componente ecológica, esboça-se aqui uma resposta operativa ao modo como podem ser analisados e projectados e qual o seu sentido prático na actualidade. 


\section{Interstício: uma analogia com o espaço}

5 Interstício, em biologia, refere-se à pequena área, orifício ou espaço existente na estrutura de um órgão ou tecido orgânico. É o espaço intercalar entre as células, moléculas, órgãos, etc. A noção estende-se a várias escalas.

Em arquitectura, por analogia, usamos o conceito de interstício para designar o espaço não edificado resultante da disposição e agregação dos edifícios. Em linguagem arquitectónica estes espaços designam-se por negativo ou vazios, por contraponto ao espaço edificado, positivo ou cheio.

7 Esta analogia nasceu da comparação daquelas cidades designadas orgânicas, espontâneas, não planeadas ou irregulares, cuja organização se assemelha profundamente a um organismo vivo e estendeu-se aos vários tipos de cidade em geral. Tal como nos tecidos orgânicos, cujos arranjos celulares delineiam espaços intersticiais de várias formas e funções, também numa cidade dita orgânica os edifícios dão origem a espaços do mesmo tipo (Figura 1).

Figura 1: À esquerda, arranjo celular da semente da ervilheira, com os respectivos espaços intersticiais, a branco ou vazios. À direita, morfologia urbana duma cidade orgânica (Martina Franca, Itália), com os edifícios a preto (positivo) e os espaços intersticiais a branco ou vazios (negativo).


Fig. 73. Células de los cotiledones de la semilla de guisante. $S t$, granos de almidón ; $a$, albúmina ('granos de aleurona "); $i$, espacios intercelulares. (De SACHS)

8 Em arquitectura, as designações "positivo» e «negativo» têm porém a conotação de forma e de fundo, respectivamente. Estas designações só por si denunciam a importância do edifício enquanto objecto de desenho. Tal facto tem levado a atribuição de menor importância ao espaço intersticial resultante da organização dos edifícios, ou seja, ao espaço público, aquele que colectivamente mais valorizamos na cidade.

9 Assim, e para além dos factores habitualmente enunciados para explicar o estado caótico das nossas cidades, especulação imobiliária, pobreza, acessibilidade, etc., verificamos que existe também uma crise de percepção do espaço intersticial enquanto forma, ou seja, enquanto objecto de planeamento e de desenho. 


\section{Interstício e o conceito de espaço exterior positivo} distintos. Observando a Figura 2 à esquerda, identificamos um espaço exterior negativo porque os edifícios nos aparecem como figura e o espaço exterior como fundo e não existe reverso. Observando a mesma figura à direita, identificarmos um espaço exterior positivo porque edifícios nos aparecerem como figuras e o espaço exterior também nos aparece como figura contra o fundo formado pelos edifícios. Dizemos então que o plano tem reverso figura-fundo (ver também Figura 3).

Figura 2: Edifícios que criam espaço exterior negativo onde vemos os edifícios como figura e o espaço exterior como fundo (esquerda) e edifícios que criam espaço exterior positivo existindo reverso figura-fundo (direita) (Alexander, 1977: 518).

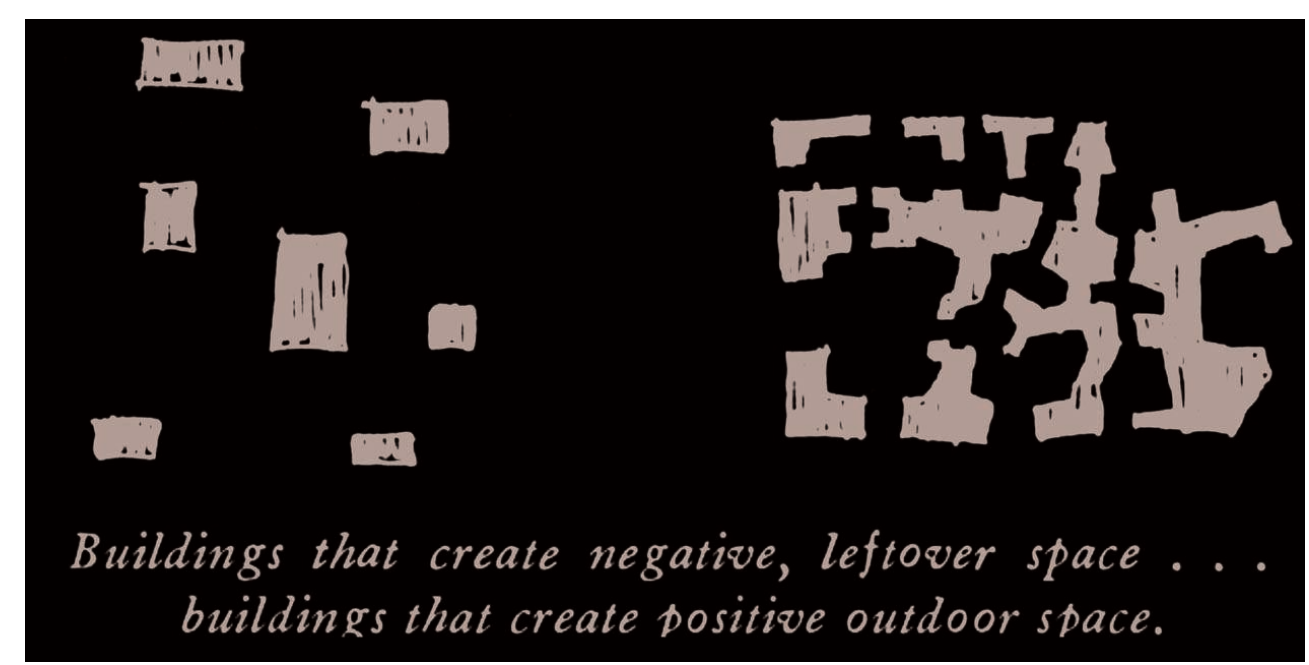

Forum Sociológico, 18 | 2008 
Figura 3: Reverso figura-fundo: Duas caras e um jarrão (Ching, 1998: 94).

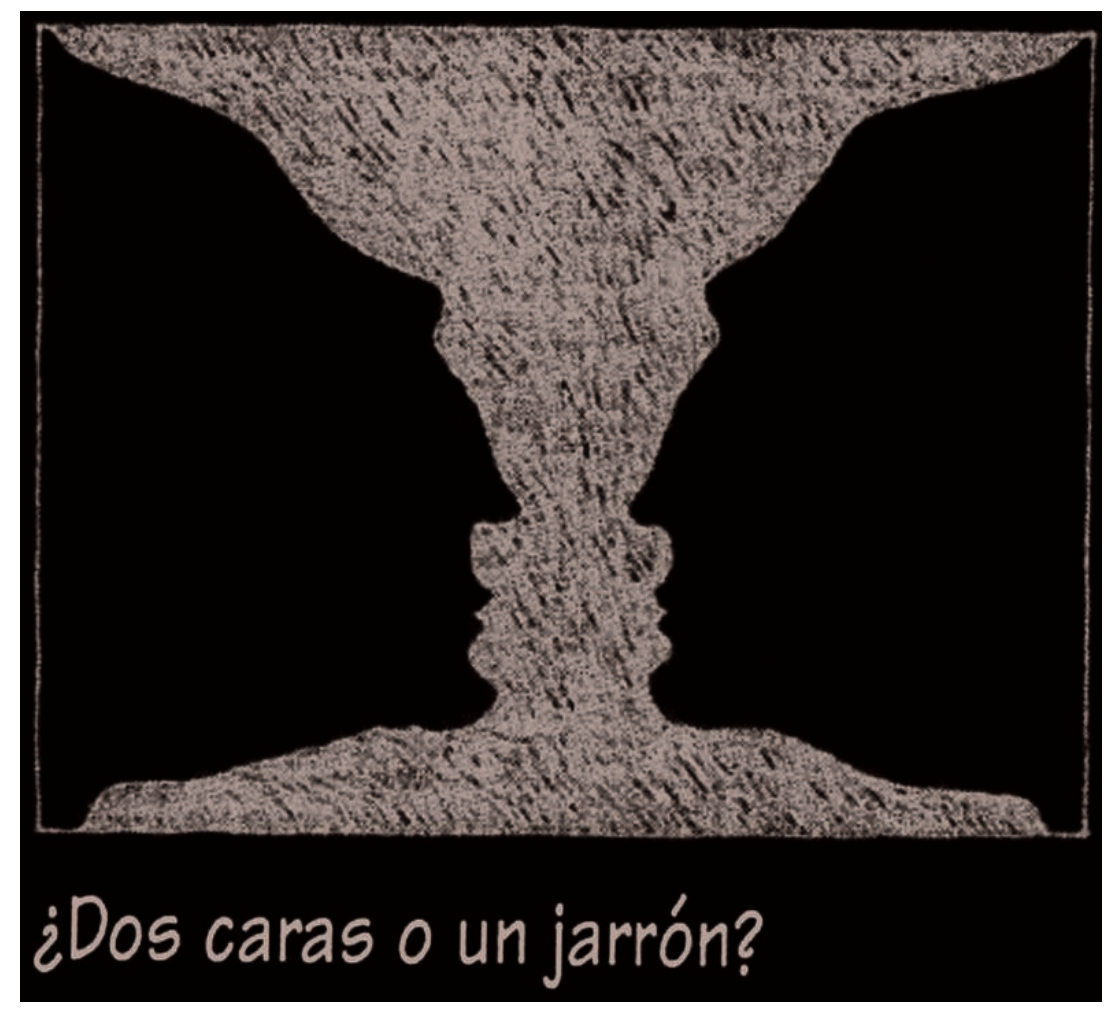

14 Segundo o mesmo autor, outra forma de definir a diferença entre espaços exteriores positivos e negativos é pelo seu grau de convexidade e de enclausura.

Conforme podemos verificar na Figura 4, um espaço é convexo quando uma linha juntando quaisquer dois pontos dentro do próprio espaço permanece totalmente dentro desse mesmo espaço. Contrariamente, quando a linha sai para fora desse espaço o mesmo não é convexo. 
Figura 4: Espaços convexos (direita) e espaços não convexos (esquerda) (Alexander; 1977: 519).

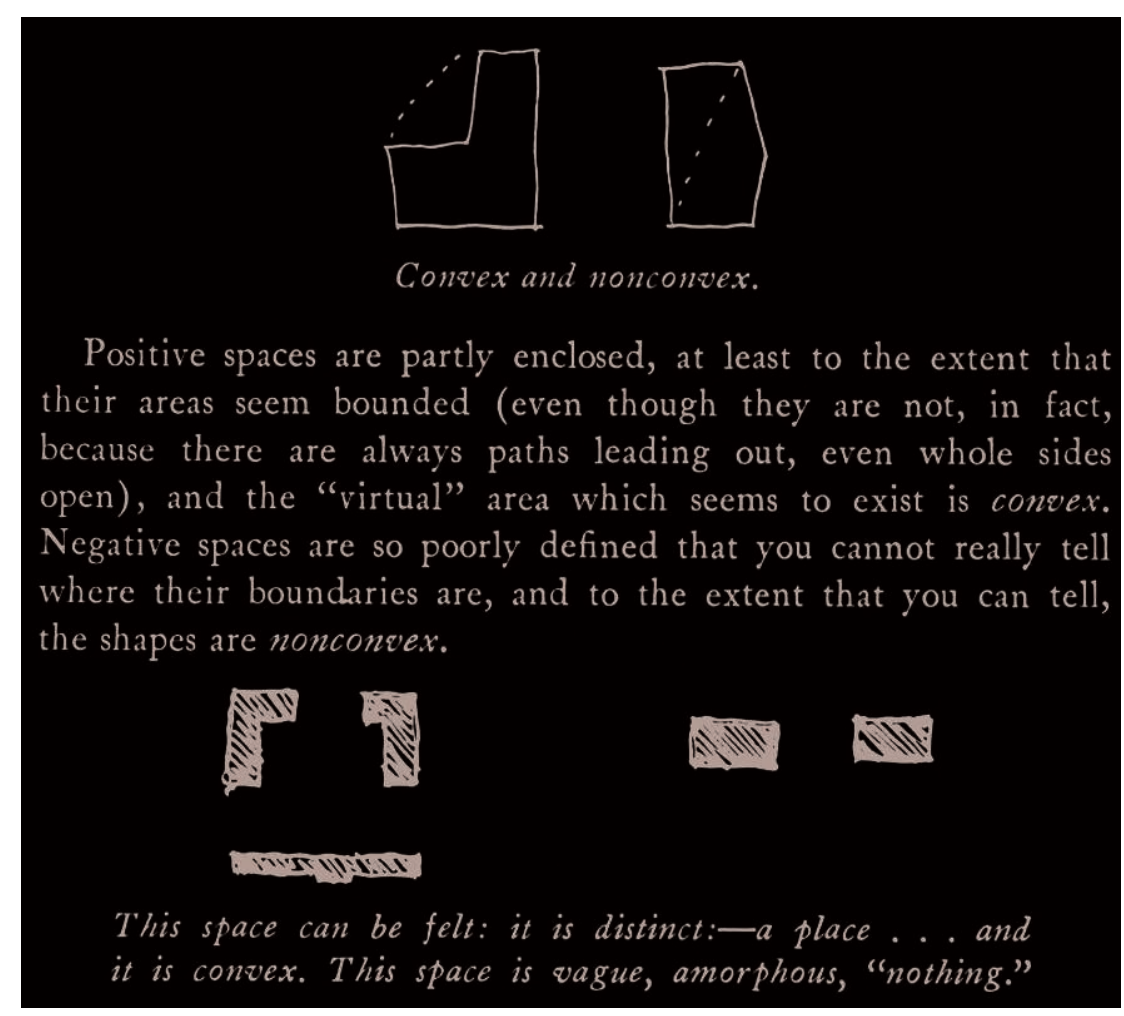

16 Num espaço exterior positivo existe sempre algum grau de enclausura dada pelos edifícios à sua volta. Existem situações em que o mínimo de edifícios colocados em pontos determinantes permitem fazer a leitura virtual da linha de contorno desse mesmo espaço.

17 Como podemos observar na Figura 1, este conceito de espaço exterior positivo está presente nas estruturas naturais e na estrutura da cidade orgânica. Tal como nas geometrias da natureza, não existem espaços residuais, tudo é programado para uma função específica.

Penso que não será difícil demonstrar que as pessoas se sentem mais confortáveis em espaços intersticiais «positivos» do que nos «negativos», sendo a apropriação destes últimos muito difícil ou mesmo impossível. Esta será talvez a melhor lição a retirar das cidades-organismo enquanto modelo de (re)construção de novos ambientes urbanos.

O conceito de espaço positivo é muito importante para o estudo da cidade enquanto objecto de arquitectura. Acredita-se que essa forma substancial em si própria é a maior contribuição para a formação duma unidade urbana coerente e coesa com alguma capacidade de auto-regulação. Digamos que "a natureza positiva do espaço é necessária para preservar a unidade do sistema" (Alexander; 2002: 261).

20 A planta de Nolli de Roma do séc. XVIII, que aparece na Figura 5, é o arquétipo deste tipo de espaço de que se vem falando. Nesta planta, tal como na Figura 1 (direita), cada bocadinho de espaço, rua, praça, edifícios e até os espaços públicos interiores é exclusivamente positivo: "não existe parte deste todo que não tenha uma forma definida e positiva. É uma compilação de entidades definidas, cada uma delas definida e substancial em si própria" (idem: 174). 
Figura 5: Planta de Nolli para Roma (Séc. XVIII). Centenas de espaços positivos (Alexander, 2002: 173).

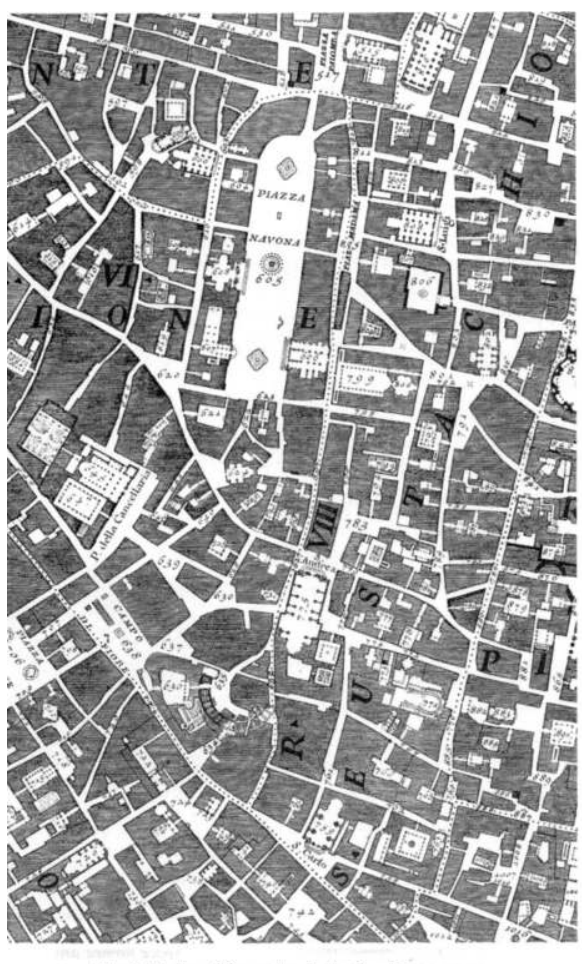

The Nolli plan of Rome: hundreds of positive spaces

Como se constroem então este tipo de espaços? Qual o seu sentido na actualidade? Como planeá-los e projectá-los? A estas questões referir-me-ei no final deste trabalho. Por agora, apenas saliento que estas formas são o resultado dum processo e o produto do desenho duma colectividade, onde cada lugar, cada rua, praça ou edifício foram concebidos com significado e propósito.

\section{Modelos de cidade e caracterização dos seus interstícios}

A forma que uma cidade deve assumir é uma questão muito antiga. Kevin Linch, no seu último livro, The Good City Form (1981), faz uma classificação de três teorias a que chama modelos normativos: modelo cósmico, modelo de cidade-

-máquina e modelo orgânico ou biológico (Linch; 1981: 75-98).

o modelo cósmico, ou o da cidade sagrada, de que a China e a Índia nos forneceram os exemplos mais desenvolvidos, toma o plano da cidade como uma interpretação do universo e dos deuses (Figura 6). Este modelo, dado o seu forte poder psicológico, influenciou fortemente o ideal da cidade da Renascença e do Barroco como forma de expressão do poder. 
Figura 6: À esquerda, cidade cósmica: um diagrama espacial de hierarquia social. Ao meio: a cidade-máquina: a construção funcional de partes interligadas. À direita, a cidade orgânica: um organismo vivo indivisível. In Spiro Kostof, The City Shaped, p. 15.

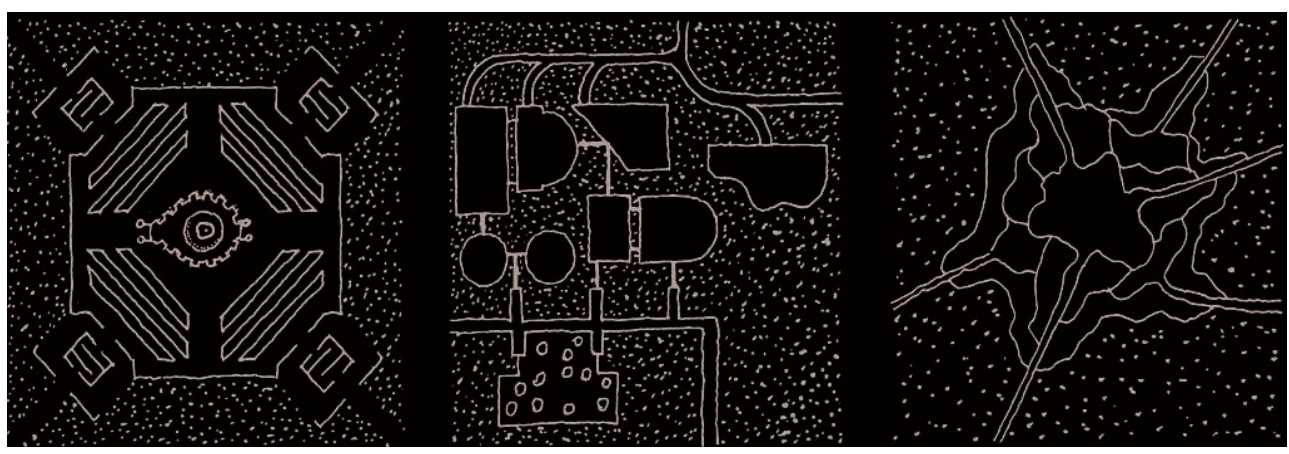

O desenho do espaço intersticial é algo muito importante e simbólico neste modelo de cidade. Os espaços públicos caracterizam-se pelos grandes eixos monumentais, o encerramento, o domínio exercido do superior sobre o inferior, o centro sagrado, o significado dos pontos cardeais, devido às suas relações com o Sol e com as estações do ano. Prevalece a quadrícula regular e a organização espacial por hierarquia. Domina a ordem, a precisão, a forma clara e o controlo perfeito do espaço. Pela importância que é atribuída ao desenho do espaço público, a sua forma tem normalmente um carácter positivo e supostamente um poderoso efeito psicológico, estabilizador de comportamentos e de união dos seres humanos.

Segundo Kevin Linch, "o poder psicológico destes dispositivos não pode ser assim tão facilmente posto de lado - os eixos, recintos, grelhas, centros e polaridades são funções da experiência humana comum e do modo como são construídas as nossas mentes. Assim, estas influências são impactos reais da forma das cidades, para o bem ou para o mal e devem ser tomadas em consideração em qualquer teoria normativa" (idem: 81).

26 No modelo máquina, o conjunto da cidade desenvolve-se por adição. Não tem qualquer significado mais abrangente; é simplesmente a soma das respectivas partes autónomas e indiferenciadas com funções e movimentos claramente diferenciados - é um plano como uma racionalidade explícita. Centra-se portanto no zonamento, na separação ordenada das actividades e nos transportes, nos processos de produção, na saúde dos trabalhadores e nos serviços públicos.

Apesar de actualmente este modelo parecer triunfante, ele não é uma concepção moderna: "foi particularmente útil sempre que os aglomerados populacionais tiveram um carácter temporário, tiveram de ser construídos à pressa, ou foram construídos com objectivos claros, limitados e práticos, tal como se pode ver em muitos locais com origens coloniais. 0 objectivo habitual era distribuir terras e recursos mais rapidamente, e proporcionar uma melhor distribuição no acesso a estes terrenos. São exemplos as colónias gregas, colónias romanas, bastides, Nova Iorque - ilha de Manhattan, a cidade radiante de Le Corbusier, disposições em grelha e cidades lineares" (idem: 83).

28 Mas os espaços intersticiais produzidos por este modelo de cidade, ao contrário do modelo anterior e do seguinte, não têm um carácter positivo e, consequentemente, são apenas espaços residuais entre os edifícios. A importância da forma do edifício em detrimento da forma do espaço exterior tem levado necessariamente à concepção deste tipo de cidade, de que são exemplo inúmeros conjuntos urbanos das nossas periferias. Neste modelo o espaço público tem sempre um carácter secundário. 0 conflito do carro 
e do peão é constante e o desconforto bioclimático também não convida à permanência nesses locais cuja função deveria ser a vida colectiva.

Por fim, o modelo orgânico ou biológico, que olha para a cidade como um organismo vivo, uma noção que surgiu com a ascensão da biologia nos séculos XVIII e XIX e que foi uma reacção à tensão provocada pela industrialização do século XIX. Apesar de o modelo orgânico ter tido menos influência na construção de cidades do que os dois paradigmas anteriores, é a perspectiva mais utilizada pelos actuais profissionais de planeamento, por ser também aquela que melhor incorpora os conceitos actuais de sustentabilidade e de ecologia.

Esta cidade tem um tamanho ideal, um limite claro e uma autonomia própria. Tal como um organismo vivo, não altera a sua dimensão pela simples extensão, dilatação ou adição indefinida das partes; antes reorganiza a sua forma à medida que muda de dimensão. A forma e a função do conjunto são complexas, não podendo ser compreendidas apenas pelo conhecimento específico das partes, uma vez que estas funcionam em sistema. Por outro lado, apesar de ter um limite bem definido, não é fácil dividi-la internamente. 0 organismo na sua globalidade é dinâmico mas é um dinamismo homeostático, ou seja, que tende para o equilíbrio. É a perspectiva dum modelo auto-regulador que também se repara a si próprio.

31 Exemplos deste tipo de cidades são as cidades-jardins de Ebenezer Howard; é também o modelo das cidades tradicionais pré-industriais de crescimento espontâneo ilustrado por muitas cidades portuguesas.

Como vimos antes, a analogia entre este modelo de cidade e um tecido orgânico é muito grande - a forma e a função estão indissoluvelmente ligadas. Na natureza não há desperdício, não existem estruturas ou espaços residuais - tudo tem uma função específica. Portanto, os espaços intersticiais têm um carácter positivo, uma qualidade estrutural inigualável. São espaços anatómicos mas também dinâmicos, que podem mudar de aspecto ao longo do ano com o devir do ciclo solar e das estações, o que provoca alterações no seu aspecto e consequentemente no seu uso. São estes espaços os mais bem-sucedidos, os mais apropriados e os que têm mais vida. As praças, pracetas ou pequenos largos, os becos e as ruelas que caracterizam este padrão orgânico de espaços positivos são ainda hoje um exemplo de espaços públicos bem-sucedidos na função a que se destinam - o uso colectivo. Por outro lado, o interior dos quarteirões, os pátios e os quintais, também eles interstícios, são um complemento importante da vida das cidades e representam microcosmos organizados dentro da malha urbana compacta característica das urbes tradicionais do Mediterrâneo.

Normalmente estes espaços apresentam uma geometria irregular mas que é coerente e conectada - o que é diferente das formas irregulares não coerentes e não conectadas. Posto isto, não podemos estar mais em desacordo com algumas afirmações habituais sobre a cidade orgânica como um exemplo de profunda desordem urbanística.

Neste contexto, podemos afirmar que os modelos de cidade enunciados correspondem a dois paradigmas ou formas de pensamento diferenciado. Um profundamente racional, cartesiano, baseado no conhecimento das partes como no modelo de cidade-máquina. $\mathrm{O}$ outro, sistémico ou holístico, baseado no conhecimento do todo, como no modelo de cidade organismo, que aborda problemas complexos como as estruturas orgânicas. 


\section{Desenhando o interstício urbano}

Procuraremos agora responder de um modo operativo à questão levantada inicialmente. Como se constrói então este tipo de espaços? Qual o seu sentido na actualidade? Como planeá-los e projectá-los? Como transformar os espaços exteriores negativos tão característicos da nossa cidade contemporânea em espaços positivos?

A resposta encontra-se nos trabalhos desenvolvidos por Christopher Alexander, o mesmo autor que identificou o conceito de espaço exterior positivo. Procuraremos de forma sucinta e operativa responder a estas questões mostrando aqui alguns aspectos do seu trabalho e método.

As Figuras 7 e 8 representam dois tipos de cidade muito diferentes, que se poderiam comparar ao modelo máquina, no primeiro caso, e ao modelo organismo, no segundo caso, conforme elucidámos acima. No primeiro caso, estamos na presença duma típica cidade moderna americana (Berkeley), que bem poderia ser certas periferias de Lisboa. No segundo caso, estamos perante um projecto para a mesma área, cujo objectivo é dar mais vida a este espaço, ou seja, torná-lo mais orgânico. Mantendo tanto quanto possível os edifícios pré-existentes, transforma-se o espaço negativo em espaço positivo, pela adição ou subtracção de edifícios, criando assim um sistema de reverso figura-fundo.

Figura 7 浊 Padrão espacial de cidade com fraca qualidade de vida urbana. Típica cidade moderna americana (Berkeley. Grande percentagem de terreno atribuído à rede viária (cinzento-escuro), passeios mínimos e descontínuos (branco), jardins privados (cinzento-claro) que circundam os edifícios (Alexander, 2005: 288).

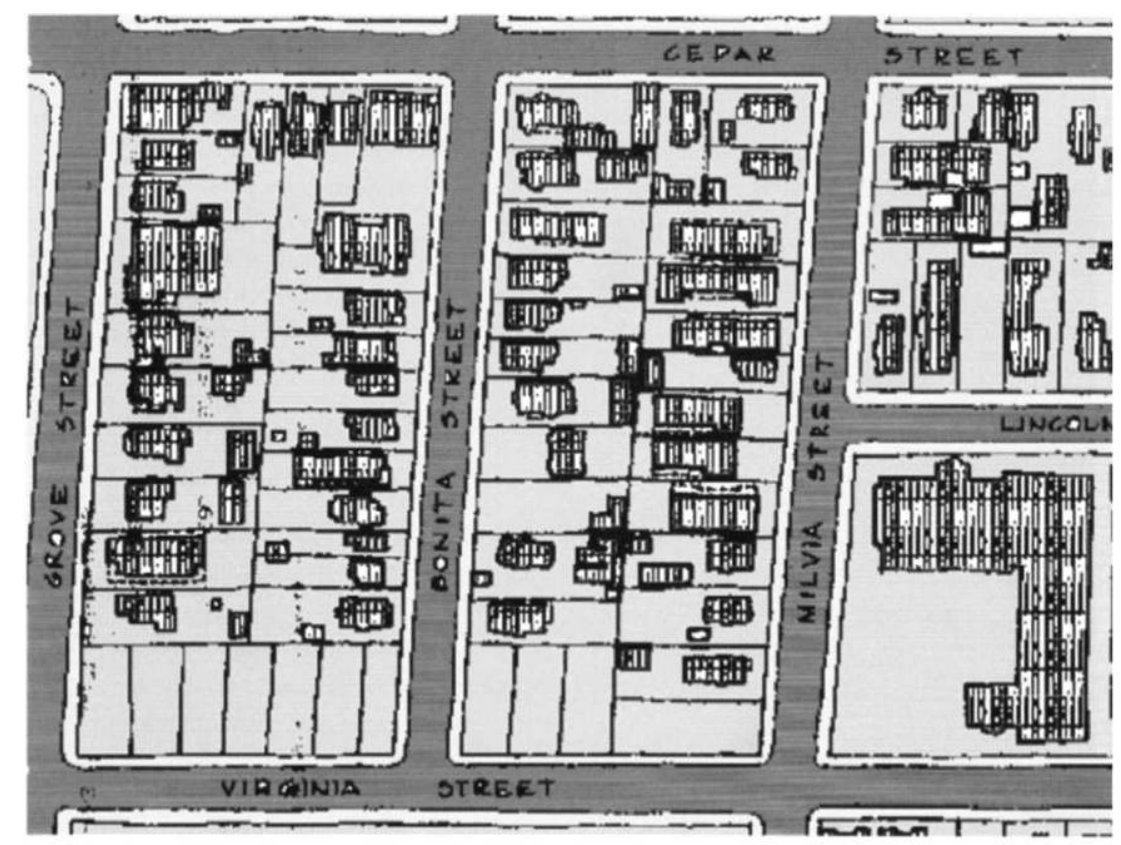

AN UNIIEALTII PATTERN: THE. 2OTH-CENTURY NORM. This drating and the one on the opposite Nuge are aluaten to the sume saule. The gross quality of this draning reflects the gross quality of the cnvironment it portrays: a fiew blocks in a typical zotb.

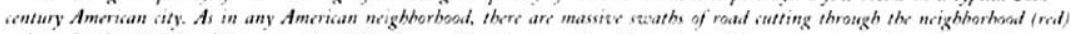
the pedestrian bull is minimal, on the thinly drawn discontinuows stidewalks (ycllow). The gardens (gren) for the most part are taasted as they sarroumd the gray (houss) in arcais 100 small to be used. 
Figura 8: Padrão espacial de cidade com elevada qualidade de vida urbana. Contrasta a área anterior (Figura 7) imaginada agora com base no modelo da cidade organismo e do conceito de espaço exterior positivo. Mantendo o mesmo número de fogos, a distribuição e a percentagem de espaço público (branco), rede viária (cinzento-escuro) e espaço verde (cinzento-claro) é completamente diferente do plano anterior. maior continuidade e quantidade do espaço público, redistribuição do espaço verde de uma forma coerente e uma rede viária minimizada e descontinuada a favor do peão (Alexander, 2005: 289).

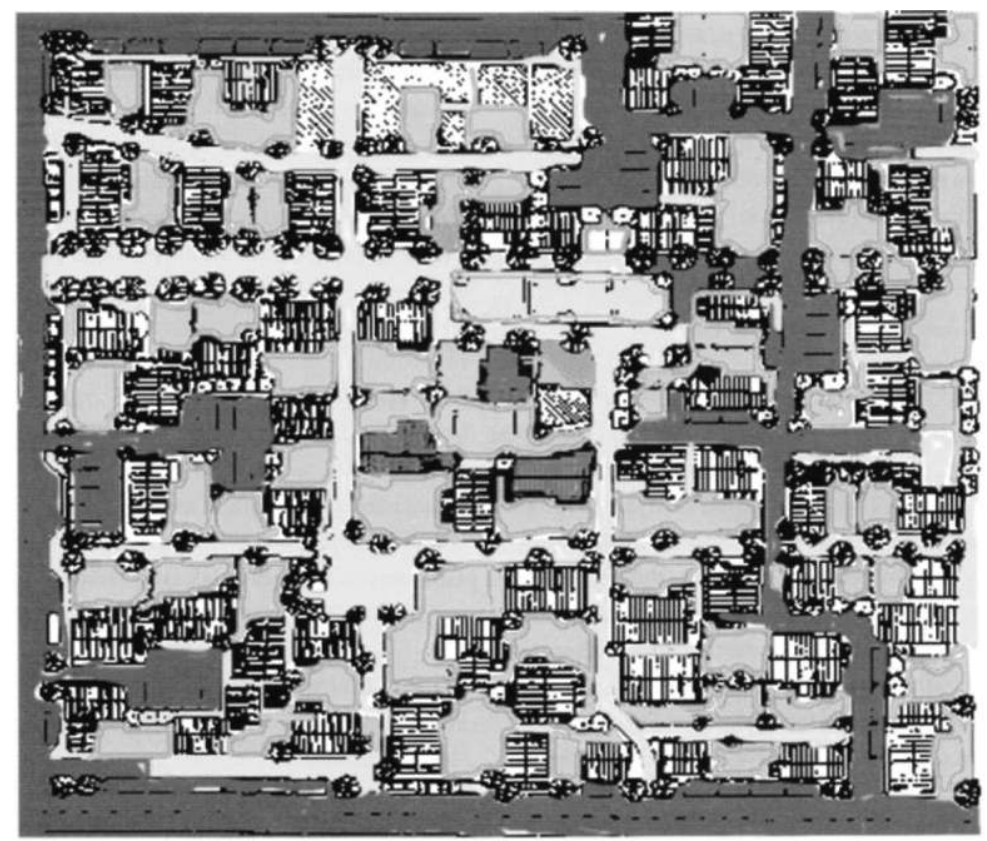

A NEW KIND OF NORM: A HEALTHY PATTERN: An imaginary neighborbood, about 450 feet by boo feet, with some 65 bouses, and perbaps zoo persons, at a density of about to dwellings to the acre. The drawing shows relative amounts of yellow, red, green and gray which are quite different from tbe previous plan. There are large amounts of yellow, tbe green is coberently sbaped, the red is minimized and discontinuous. In part, this plan simulates the process generated by the principles defined in the following pages. Cbristopber Alexander and Saul Picbardo. Center for Environmental Structure, 1996.

As cores representam os diferentes layers de ocupação do terreno: Branco - espaço para peões, incluindo praças e caminhos ou passeios; Cinzento-claro - jardins privados ou públicos ou semi-privados; Cinzento-escuro - rede viária, incluindo estacionamento. Além disso, ainda temos o layer dos Edifícios, que inclui a habitação, o comércio e os serviços. Segundo o autor deste projecto, o carácter fundamental dum bairro depende do modo como estes quatro elementos são articulados, da mesma forma que uma molécula orgânica tem as suas características em função da articulação dos seus quatro elementos (o carbono, hidrogénio, oxigénio e nitrogénio). A leitura por layers dos diferentes elementos dá-nos à partida e em simultâneo uma visão do todo e das partes, que por sua vez também são todos, no caso da Figura 8 (Alexander; 2005: 288).

As Figuras 7 e 8, representam a mesma área, com a mesma densidade, o mesmo número de fogos, o mesmo número de carros, e no entanto elas apresentam-se com um padrão completamente diferente. Poder-se-á dizer que o primeiro tipo de cidade prima pelo seu individualismo e descontinuidade - a rede viária é invasiva, os passeios são estreitos e os espaços verdes são privados, diminuindo assim a oportunidade para o contacto humano e a vida colectiva. Os edifícios, mesmo respeitando um alinhamento, não conseguem gerar espaços exteriores de qualidade por melhor que seja a sua arquitectura. No segundo caso, a cidade prima pelo colectivismo e pela continuidade através da criação de espaços públicos segregados dos automóveis, contínuos e hierarquizados e a agregação dos espaços verdes duma forma mais sustentável. A disposição dos edifícios procura conformar os espaços exteriores de uma forma 
positiva, com formas definidas, coerentes e com funções específicas. É dada primazia aos espaços pedonais (brancos) que através da sua continuidade e subsidiariedade formam uma estrutura hierarquizada (um sistema).

O padrão espacial de cidade representado na Figura 8 é pois inspirado no modelo orgânico ou biológico, cuja qualidade dos interstícios urbanos passa pelo carácter positivo dos seus espaços exteriores. A validade deste modelo na actualidade e eventualmente no futuro residirá na sua intemporalidade.

\section{Conclusão}

41 Uma primeira evidência que resulta deste trabalho relativamente aos interstícios urbanos é que estes podem ser de dois tipos: apenas espaços residuais e sem forma (negativos) ou espaços com forma (positivos), onde toda a porção de espaço tem um significado próprio e uma função específica, tal qual as estruturas da natureza. Esta diferenciação repercute na forma como as pessoas apropriam o espaço urbano; muito mais intensa nos espaços públicos com carácter positivo e com grande dificuldade nos espaços com carácter negativo.

Verifica-se também que os interstícios urbanos positivos estão associados essencialmente ao modelo de cidade orgânica. Esta qualidade estrutural, que está também presente nos tecidos dos seres vivos, falha redondamente nas grandes expansões urbanas recentes, caracterizadas pelo carácter residual dos seus espaços exteriores.

Por último, mostrámos como é que estes espaços residuais podem ser convertidos em espaços positivos. Para tanto é necessário (mas também em princípio suficiente) mudar o paradigma de fazer cidade, tomando como objecto de estudo o espaço público em lugar do edifício. A malha urbana que assim se vai cerzindo, pontualmente, localmente, cirurgicamente, torna-se com o tempo uma estrutura urbana mais orgânica e autoreguladora e portanto com mais vida.

\section{BIBLIOGRAFIA}

ALEXANDER, C. (2005), "A Vision of a Living World", The Nature of the order: An Essay on the Art of Building and the Nature of the Universe, Volume 3, Berkeley California, The Center for Environmental Structure.

ALEXANDER, C. (2002), “The Phenomenon of Life”, The Nature of the order: An Essay on the Art of Building and the Nature of the Universe, Volume 1, Berkeley California, The Center for Environmental Structure.

ALEXANDER, C. (1977), A Pattern Language, New York, Oxford University Press.

CHING, F. (1998), Forma Espacio y Ordem, Barcelona, Edicciones Gustavo Gilli. 
KOSTOF, S. (1999), The City Shaped: Urban Patterns and Meanings Through History, London, Thames and Hudson.

LINCH, K. (1981), A Boa Forma da Cidade, Colecção Arquitectura \& Urbanismo, Lisboa, Edições 70.

\section{RESUMOS}

Tal como nos tecidos orgânicos, cujos arranjos celulares delineiam espaços intersticiais de várias formas e funções, também numa cidade a organização dos edifícios dá origem a espaços do mesmo tipo. Em linguagem arquitectónica, estes espaços designam-se habitualmente por negativo, ou seja, o fundo sobre o qual os edifícios (forma) assentam. Tal facto tem levado à atribuição de menor importância ao desenho dos espaços intersticiais na cidade moderna. Nas cidades ditas orgânicas, forma e fundo quase não se distinguem, ou melhor os dois distinguem-se como forma. Assim, do ponto de vista urbano tem muito interesse tomar como objecto de estudo, ou seja, como forma, o espaço de fundo definido pelos edifícios - interstícios urbanos. 0 carácter positivo destes espaços traduz-se numa qualidade estrutural fundamental para sua vivência e utilização.

As an organic tissue, the interstitial spaces of various shapes and functions outlined by cellular arrangements, also the organization of buildings in a city leads to spaces of the same type. In architectural language, these areas are called 'the negative', which means the background by opposition of the shape of the buildings. This fact has led to diminishing the importance of the design of interstitial space in the modern city.

In organic cities, shape and background are hardly distinguished, or by another words the two stand out as shape. Thus, it has great interest from the urban point of view, to study the quality of these interstitial spaces. The positive nature of these spaces is reflected in a structural quality essential for their experience and use.

\section{ÍNDICE}

Keywords: building vs interstitium, shape vs background, positive space vs negative space

Palavras-chave: edifício vs interstício, forma vs fundo, positivo vs negativo 